AAM - Author's accepted

$>$ manuscript

\title{
Cardiac Electrical and Mechanical Alterations - United in the Long QT Syndrome
}

Haugaa $\mathrm{KH}^{1,2,}$ Stokke $\mathrm{MK}^{1,2}$

${ }^{1}$ Center for Cardiological Innovation, Dept. of Cardiology, Oslo University Hospital, Rikshospitalet, Norway

${ }^{2}$ Institute of Clinical Medicine, Faculty of Medicine, University of Oslo, Oslo, Norway

The authors report no relationships that could be construed as a conflict of interest.

Word count: 1198

\section{$\underline{\text { Corresponding author: }}$}

Associate Professor Kristina H. Haugaa, MD, PhD

Dept. of Cardiology, Oslo University Hospital, Rikshospitalet

Sognsvannsveien 20, 0372 Oslo, Norway / PO Box 4950 Nydalen, 0424 Oslo, Norway

Fax number +4723073530, Telephone number +4723071393

E-mail: Kristina.Haugaa@medisin.uio.no 


\section{Cardiac Electrical and Mechanical Alterations - United in the Long QT Syndrome}

"The division of our culture is making us more obtuse than we need be."

(C.P. Snow, The Two Cultures and the Scientific Revolution)

C.P. Snow famously lamented the great divide and lack of understanding between the Natural Sciences and the Humanities in Western society, i.e. the Two Cultures. The same could be said about cardiovascular scientists today: One culture concerned about myocardial mechanics, the other about cardiac electrophysiology. This separation of power is unnecessary and inadequate in cardiac physiology and pathophysiology. Ever since the work of Galvani in the late $18^{\text {th }}$ century, we have known that the core of cardiac physiology is electromechanical. Nevertheless, electrophysiologists may still show limited interest in modern understanding of myocardial mechanics, and researchers investigating myocardial contraction do not always focus on the heart as an electrical organ.

For a long time, this divide was well illustrated by the long QT syndrome (LQT): Recognized by prolonged repolarization and increased risk of lethal arrhythmias, this syndrome was solely the domain of electrophysiologists. However, already 27 years ago, Nador and colleagues from the Schwartz group described "unsuspected echocardiographic abnormality in the long QT syndrome" (1). Subsequent work from the same group, and later publications from our own group, showed that this channelopathy was not a purely electrical disease (2), but had a mechanical aspect that was associated with increased risk of arrhythmias (3-5).

Work by Ziupa and colleagues presented in this issue of International Journal of Cardiology take us further along this fruitful path: They used state-of-the-art methods (tissue phase mapping MRI) to study mechanical function in a transgenic rabbit model of LQT1 with a clearly prolonged QT interval (6). At baseline, no systolic or diastolic differences were found between contractile function in LQT1 and wild type rabbits. However, with an even further prolongation of the ventricular action potential provoked by $\mathrm{I}_{\mathrm{Kr}}$-blockade, systolic contractile velocities increased in LQT1, while diastolic velocities decreased. These changes were directly correlated to the changes in QT interval. Combined with their previous work on an LQT2 model (7), the work by Ziupa and colleagues show that research on long 
QT syndrome can help the effort to better understand the electromechanical changes in LQT, and in general.

Should we be surprised that a prolonged QT interval is associated with mechanical perturbations? In LQT1 the prolongation of the QT interval is the result of delayed repolarization of the action potential, allowing prolonged influx of $\mathrm{Ca}^{2+}$, or even a second peak if early afterdepolarizations occur. All else being equal, at resting heart rates this could contribute to improved systolic function, but slower relaxation, i.e. diastolic dysfunction. From clinical experience, however, we have not observed "supernormal" systolic function in LQT patients, but we have reported a slight diastolic impairment in LQT and in LQT2 patients in particular (8), supporting the findings from Ziupa et al. From the current study, we can speculate that at higher heart rates, the prolonged action potential duration could prevent recovery of L-type $\mathrm{Ca}^{2+}$ channels before the next beat, thereby limiting peak $\mathrm{Ca}^{2+}$ current and systolic function. By strain echocardiography, we observed a subclinical reduction in systolic function at rest in patients with LQT2 in a study including almost 200 LQTS patients, suggesting that the electrical changes in these patients have negative mechanical consequences. Systolic function in LQT patients at higher heart rates or at exercise has not been investigated. An obvious next step for Ziupa and colleagues would therefore be to study mechanical function in their rabbit models during adrenergic stress and high heart rates.

Several studies in recent years have contributed to electromechanical perspectives in LQT: It is well established that the substrate for arrhythmias in LQT1 is myocardial heterogeneities in the action potential duration. This electrophysiological phenomenon might also be reflected in mechanical heterogeneities that are detectable by modern echocardiography, i.e. mechanical dispersion $(3,4)$, which is also associated with arrhythmias in LQT.

A probably related phenomenon is the electromechanical window (9). Normally, repolarization (QTend) ends slightly before, or simultaneous with, the end of mechanical relaxation (aortic valve closure). With prolongation of the action potential, this situation is reversed, with a QTend after aortic valve closure, resulting in a "negative electromechanical window" with increased risk of ventricular arrhythmias. This electromechanical phenomenon may be affected and even normalized by left cardiac sympathetic denervation in patients with LQT, supporting the close relation 
between sympathetic stimulus, QT interval and contraction duration (10). Future studies need to clarify whether these electromechanical aspects of LQT are only markers of electrophysiological perturbations or independent problems that need separate attention in the follow up of these patients. The past 30 years have shown that proper electromechanical studies will improve our insight in cardiac physiology and hopefully pave the path for a more integrated approach to arrhythmia syndromes.

1. Nador F, Beria G, De Ferrari GM, Stramba-Badiale M, Locati EH, Lotto A, Schwartz PJ, Unsuspected echocardiographic abnormality in the long QT syndrome. Diagnostic, prognostic, and pathogenetic implications, Circulation. 84 (1991) 1530-42.

2. De Ferrari GM, Schwartz PJ, Long QT syndrome, a purely electrical disease? Not anymore, European heart journal. 30 (2009) 253-5.

3. Haugaa KH, Amlie JP, Berge KE, Leren TP, Smiseth OA, Edvardsen T, Transmural Differences in Myocardial Contraction in Long-QT Syndrome: Mechanical Consequences of Ion Channel Dysfunction, Circulation. 122 (2010) 1355-63.

4. Haugaa KH, Edvardsen T, Leren TP, Gran JM, Smiseth OA, Amlie JP, Left ventricular mechanical dispersion by tissue Doppler imaging: a novel approach for identifying high-risk individuals with long QT syndrome, European heart journal. 30 (2009) 330-7.

5. De Ferrari GM, Nador F, Beria G, Sala S, Lotto A, Schwartz PJ, Effect of calcium channel block on the wall motion abnormality of the idiopathic long QT syndrome, Circulation. 89 (1994) 2126-32.

6. Ziupa D, Menza M, Koppermann S, Moss R, Beck J, Franke G, Feliz SP, Brunner M, Mayer S, Bugger H, Koren G, Zehender M, Jung BA, Seemann g, Foell D, Bode C, Odening KE, Electromechanical (dys-)function in long QT syndrome type 1, International Journal of cardiology. (2018). 7. Odening KE, Jung BA, Lang CN, Cabrera Lozoya R, Ziupa D, Menza M, Relan J, Franke G, Perez Feliz S, Koren G, Zehender M, Bode C, Brunner M, Sermesant M, Foll D, Spatial correlation of action potential duration and diastolic dysfunction in transgenic and drug-induced LQT2 rabbits, Heart rhythm : the official journal of the Heart Rhythm Society. 10 (2013) 1533-41.

8. Leren IS, Hasselberg NE, Saberniak J, Haland TF, Kongsgard E, Smiseth OA, Edvardsen T, Haugaa KH, Cardiac Mechanical Alterations and Genotype Specific Differences in Subjects With Long QT Syndrome, JACC Cardiovascular imaging. 8 (2015) 501-10.

9. ter Bekke RM, Haugaa KH, van den Wijngaard A, Bos JM, Ackerman MJ, Edvardsen T, Volders PG, Electromechanical window negativity in genotyped long-QT syndrome patients: relation to arrhythmia risk, European heart journal. 36 (2015) 179-86.

10. Schneider AE, Bos JM, Ackerman MJ, Effect of Left Cardiac Sympathetic Denervation on the Electromechanical Window in Patients with either Type 1 or Type 2 Long QT Syndrome: A Pilot Study, Congenital heart disease. 11 (2016) 437-43. 